\title{
Honoring Practical Processing Science at TMS 2020
}

\author{
ADAM PILCHAK (10 ${ }^{1,2}$ \\ 1.-Air Force Research Laboratory, Materials and Manufacturing Directorate (AFRL/ \\ RXCM), Wright-Patterson Air Force Base, OH 45433, USA. 2.-e-mail: adam.pilchak.1@us.af.mil
}

The art of extracting metals from their ores and then melting the metal to produce alloys that are cast into ingots, converted to billets, forged into shapes that are heat treated, quenched, stress relieved, machined, and subjected to surface treatments before being placed into service lives that may exceed 60 years in the harsh environment of a gas turbine engine is nothing short of miraculous. Consider further that each step may consist of many individual steps. Some open die forging operations, for example, may consist of more than 100 combinations of rotations, translations, upsets/draws, repositioning the part, and reheating. Furnace temperatures, heating and cooling rates and time at temperature must be controlled and some demanding applications must be quenched within seconds to make their solution heat treatments effective. There are so many different alloys being forged into a wide variety of shapes and section thicknesses for many different industries (automotive, aerospace, defense, construction, medical/ biomedical). Coupled with the complexity of these operations, it is no surprise that Edisonian-based approaches to optimizing forging practices could quickly bankrupt a supplier, and reduction of scientific knowledge gained in the laboratory to practice is difficult given all the potential sources for variability.

It was clear early to those in the industry that practical methods and models would be needed to help guide process development and this is exactly what a small group of scientists and engineers at Battelle Memorial Institute set out to work on in the late 1970s. With combined expertise in mechanics, metallurgy, processing science, and computational methods, Taylan Altan, Soo-Ik Oh, Wei Tsu Wu, and

Adam Pilchak and John Rotella are guest editors for the Titanium Committee, Shaping and Forming Committee, and ICME Committee of TMS, and coordinated the topic Practical Research in Processing Science in this issue.

(Received August 6, 2020; accepted August 11, 2020; published online September 8, 2020)
Lee Semiatin were constantly advancing the state of the art in the processing of metallic materials; often before the rest of the world was ready for it. For example, their team was the prime contractor for the very first Air Force Materials Lab Processing Science Program. During this program, the team developed (what we call now) a foundational engineering problem using integrated computational materials engineering (ICME) to optimize the process for creating a dual-microstructure/dual-property Ti-6Al-2Sn-4Zr-2Mo disk-and they did this $\sim 25$ years before the widespread adoption of ICME in our community (Fig. 1).

These four were masters of understanding processes and developing practical simulations of them. They devised elegant and convincing validation experiments and paid careful attention to boundary conditions, process parameters, and material behavior under relevant processing conditions. Their work at Battelle and that which followed when they each went their separate ways has touched every facet of metals processing including: solid, liquid, and vapor phase processes, power and wrought metallurgy, conventional and solid state joining processes, high-speed machining processes, and additive manufacturing (a decade before the current explosion of effort). Their work touched a vast array of technologically important materials including titanium and its alloys, nickel-base and cobalt-base superalloys, aluminum alloys, various intermetallics, and high entropy alloys, among others. The contributions of Altan, Wu, Oh, and Semiatin to the field of processing science are so vast and impactful that it was only fitting to honor their lifetime of achievements at the TMS 2020 Annual Meeting \& Exhibition at "Purveyors of Processing Science and ICME: A Symposium to Honor the Many Contributions of Taylan Altan, Wei Tsu Wu, Soo-Ik Oh, and Lee Semiatin."

Paying homage to the honorees' lifelong commitment to developing and validating process models, the symposium remained alloy-agnostic and instead kept central themes of processing, process 


\title{
COMPUTER-AIDED MANUFACTURE OF DUAL-PROPERTY COMPRESSOR DISK
}

MATERIAL MODELING

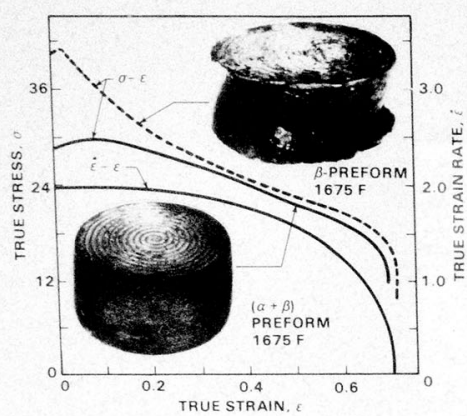
- CONSTITUTIVE REACTIONS
- FORMING LIMIT
- PROCESSING/MICROSTRUCTURE/
PROPERTY RELATIONSHIPS
PROCESS MODEL

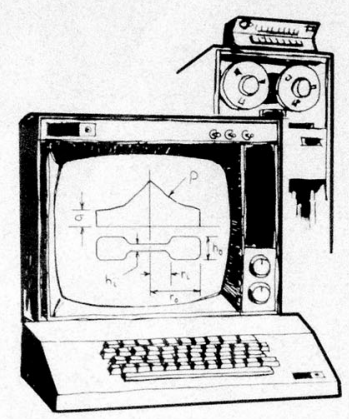

- finite element modeling to PREdict - STRAIN

- STRAIN RATE

- STRESS

- TEMPERATURE DISTRIBUTION

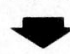

\section{INTERFACE MODEL}

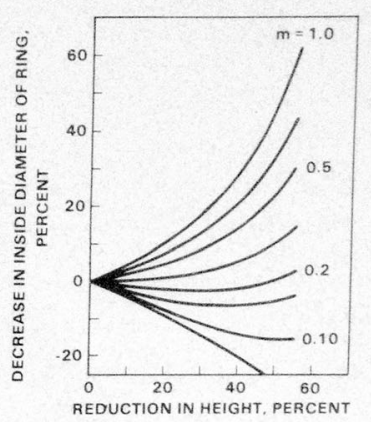

- fRiction factors for flat AREAS/FLANGE SECTIONS

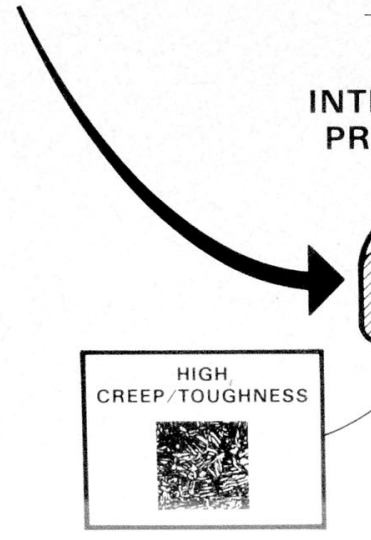

\section{INTEGRATED SYSTEM FOR} PROCESS OPTIMIZATION

\author{
$R$
}

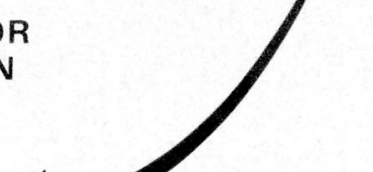

PROCESS MODELING AND COMPUTER TECHNIQUES TO DETERMINE PROCESS AND

MATERIAL PARAMETERS FOR MANUFACTURING DUAL-PROPERTY COMPRESSOR DISK

Fig. 1. A poster that's been hanging in Lee Semiatin's office as long as he's been at the Air Force that documents early visions of ICME resulting from the Processing Science Program performed while the honorees were at Battelle Memorial Laboratories

simulation, and modeling the evolution of microstructure/texture/defects during processing. The symposium consisted of 37 technical talks organized into six technical sessions (Superalloys, Additive Manufacturing, Titanium alloys, Modeling and Simulation, Enhanced Properties via Thermomechanical Processing, and finally, Advances and Challenges in ICME). There were a large number of (28) invited talks where each speaker received 30-min allowing them to do thorough treatment of their subjects. Overall, the approach to inviting many speakers contributed to the high quality of the symposium and was well-received by the audience (which was in the range of 25 to 55 per talk, with an average of 33). There was excellent participation from industry, academia, and government laboratories. Additionally, there were three international participants, Drs. Nathalie Bozzolo, Philip Prangnell, and Joao Quinta da Fonseca.

The symposium opened with comments by Adam Pilchak, which included a brief presentation recalling the "Air Force Processing Science Program" which brought our honorees together initially, and which resulted in those early visions of ICME (Fig. 1). The opening comments concluded with a great big CONGRATULATIONS to one of the honorees, Lee Semiatin, for his recent induction into the National Academy of Engineers and, finally, the presentation of the plaques from TMS and a special token for each of the honorees to commemorate the event. 


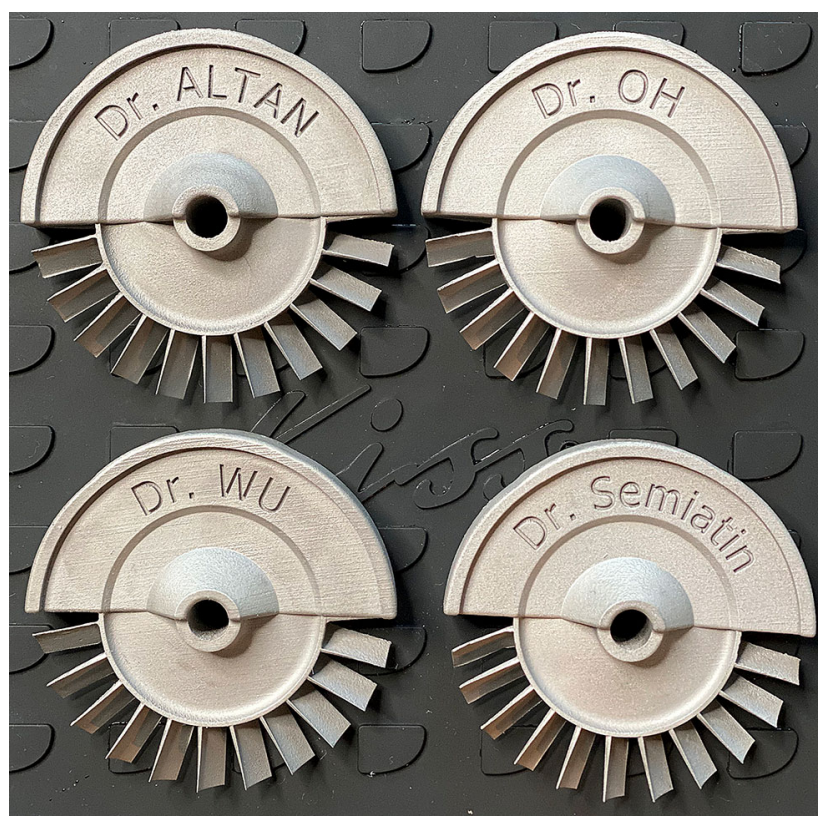

Fig. 2. Laser-powder-bed additively manufactured cobalt-chrome personalized half-disk-half-forging mementos given to each of the honorees

On that note-our honorees were so dedicated to the development of practical methods and models for metal forming that it seemed only fitting that the memento reflected this in some way. Moreover, their work touched virtually every aspect of metals processing from ingot to finish forging, machining, and surface treatment. It was a tall order, but an idea emerged from a discussion with my colleague John Rotella at AFRL: create a 3D model of a small, representative turbine engine disk, and then revolve a geometry of a representative closed-die forging around half of that component to create a hybrid - half forging and half finish-machined integrally bladed rotor (IBR). Of course, the only way to manufacture such a beast would be by additive manufacturing.

The piece was created by Ayman Salem from Materials Resources $\left(\mathrm{MRL}^{1}\right)$. Having worked with Semiatin for about 20 years, Ayman and his team quickly went to work and laser powder bed additively manufactured these four mementos out of a cobalt-chrome alloy. The parts were given an $800 \mathrm{~F}$ stress relief for $30 \mathrm{~min}$. Afterward, the support structures were removed by hand and they were grit blasted to produce the beautiful pieces you see in Fig. 2. I picked up the parts just before leaving for the airport. Upon arriving in San Diego I immediately went to interview Semiatin as part of AIME's Oral History Project ${ }^{2}$. That was quite an experience, and I encourage you to listen to the interview with Lee when it is released and also consider listening to the entire series!

The papers for this special topic were contributed from the Purveyors of Processing Science Symposium. Three articles are featured that span a range of topics and technical breadth. In the first, the team from ATI Metals led by Bruce Antolovich reviews physical and numerical simulation methods and their utility in the metals supply chain. The authors cover six interesting case studies in processing of aerospace materials. In the second paper, Malik et al. have investigated the effect of friction stir processing, with and without additions of zinc oxide, on the corrosion behavior of the aluminum alloy AA1050. Finally, Brunson et al. attempt to tackle one of Semiatin's favorite problems, namely, preferential selection of alpha phase variants during decomposition of metastable beta titanium according to the Burgers orientation relationship. In this third article, Brunson et al. develop a single framework that can assess the energetics of the transformation due to the presence of other nearby alpha variants or in the presence of an internal or external force. While the derivations in the paper by Brunson et al. may not easily pass as practical processing science, the final model is meant to be exactly that! It is fast-acting and combines the capabilities of various other approaches into a selfconsistent framework and hence, may be suitable for industrial applications.

Finally, I want to extend a great big THANK YOU to everyone who participated in the Honorary Symposium by presenting a paper, chairing a session, or attending a talk. You all made it a very memorable event!

The papers in this special topic, Practical Research in Processing Science, can be accessed via the October issue's Table of Contents page at $h$ ttps://ink.springer.com/journal/11837/72/10/page/1.

\section{REFERENCES}

1. http://www.icmrl.net.

2. http://aimehq.org/programs/oralhistories.

Publisher's Note Springer Nature remains neutral with regard to jurisdictional claims in published maps and institutional affiliations. 